\title{
Combination Condom Use and Natural Family Planning Method To Control Pregnancy Among Fertile-Aged Couples In Moslem Community
}

\author{
Andi Asmawati Azis \\ Universitas Negeri Makassar \\ Makassar, Indonesia \\ andi.asmawati@unm.ac.id
}

\author{
Irma Suryani Idris \\ Universitas Negeri Makassar \\ Makassar, Indonesia
}

\author{
Andi Mulawarman \\ Family Planning Board of Makassar \\ City \\ Makassar, Indonesia
}

\begin{abstract}
This quasi experiment research concerned and to increase knowledge level fertile aged couple in Makassar Moslem's community, the various attitudes about birth control among subjects after intervention, Husband's engagement after intervention, the effectiveness of the combination between natural family planning; and condom use among subject and The influence of knowledge, attitudes, social norms, beliefs, to support from the couple to succeed the intervention process. All fertileaged couples in community used as population subject. Selected sample $(n=37)$ by purposive sampling method. The data collected by questionnaires. The effectiveness was assessed by failure and successful to pregnant or not pregnant during this research is independent variable, meanwhile the dependent variables incorporates social, cultural and individual factors. This research conducted a descriptive analysis, Shapiro Wilk method was used as a normality test, bivariate analysis with the Wilcoxon and Chi square test and multivariate analysis using logistic regression analysis $(\alpha=5 \%)$. Natural family planning with the use of combination condom had influenced the success of Moslem woman's pregnancy through 5 factors: knowledge $(\mathrm{OR}=7)$, support from partners $(\mathrm{OR}=5)$, social norms $(\mathrm{OR}=4)$, belief $(\mathrm{OR}=3)$, and attitude $(\mathrm{OR}=1)$.
\end{abstract}

Keywords - natural family planning; combination condom use; fertile-aged couples

\section{INTRODUCTION}

Developing countries is experiencing demographic problems due to population growth. Sustainable development as a guide for developing countries faces educational, water and housing issues. Furthermore, various countries are organizing a population-limiting program.

Indonesia's population growth can be suppressed by intervention with family planning program. However, the fact that since 2010 until today still drove about 1.49 percent per year, even Contraceptive Prevalence Rates tend to increase at least in last decades. Influential factors can be obstacles such as lack knowledge, misconceptions, fear of side effects, limited purchases, restrictive laws, provider bias, excluded from data, stigma, the gender issue, social norm or local cultural and religious factors. The last factor was emerge in some places in Indonesia, especially in certain community. It was also supporting Unmet Need Rates (9\%).
According to the concept of behavior, knowledge and attitude of a person plays an important role in decision making. One's involvement in a program is influenced by his knowledge. The benefits of birth control programs with the introduction of contraceptives should be understood by the community. With their knowledge, they will engage consciously.

In Moslem's community of Islamic Boarding School, the average number of children a lot, Patriarchy culture dominate decisions in the family, modern family planning methods has not been fully accepted in their institutional by cultural and religious aspect except in an emergency. To increase pregnancy rates control, it would require educational intervention model which familiar in their own community, ie. natural family planning/NFP (coitus interruptus, calendar system, cervix mucus observation, lactation amenorrhea) and supporting with promotion about reproductive health and family planning program including condom use as a combination method to reduce NFP failure rates.

The objectives of this research are: (1) to find out the increasing of knowledge level among subjects (2) to know the various attitudes about birth control among subjects after intervention (3) explaining how Husband's engagement that will increase after intervention according to contribution for decision to choose coitus interruptus or condom or combination of both infertile period. (4) to find out the effectiveness of the combination of natural family planning and condom use is a significant success for pregnancy control among subject. (5) explained the influence of knowledge, attitudes, social norms, beliefs, and support from the couple to succeed the intervention process.

\section{RESEARCH METHOD}

This study was conducted in January-June 2013 in one of Islamic Boarding School in the city of Makassar and Laboratory of Biology, Universitas Negeri Makassar to follow up the result of tests such as cervix mucus, LH, and basal temperature, it is for the accuracy comparison of the calendar system. It is Quasi-Experiment with pre-post control design by giving intervention about NFP, family planning program and 
reproductive health training. Precede-proceed Model by L. Green was used as a framework theory.

All fertile-aged couples in the community used as population subject. Selected sample $(n=37)$ by purposive sampling method, were agree and committed to participate. The materials needed during the training are presentation equipment (notebooks, LCD, handbook, powerpoint slide, video) and observation sheets (calendar system, cervical mucus, days of coitus, contraception used). The data collected by questionnaires. The effectiveness was assessed by failure and successful to pregnant or not pregnant during this research is the independent variable. Meanwhile, the dependent variables incorporate social, cultural and individual factors. Descriptive analysis, Shapiro-Wilk method was used as a normality test, bivariate analysis with the Wilcoxon and ChiSquare test and multivariate analysis using logistic regression analysis $(\alpha=5 \%)$.

\section{RESUlt AND DisCUSSION}

The average age of the subject is 30.8 years old, $62.2 \%$ have an undergraduate education, $40.5 \%$ had no plans on the number of children, generally subject has a normal nutritional status $(62.2 \%)$, average of menstrual duration is 6.1 days, $83.7 \%$ of them have menstrual cycle length between 25-35 days.

The level of knowledge on family planning method and program among subjects increased significantly after the intervention (10-54 point to $16-56$ point on average from 34.3 to 41.7). There are 27 among subjects is identified having a good knowledge at least on medium level after the intervention.

Knowledge NFP subjects increase because the teaching special about fertility from researcher as teacher NFP. NFP training is effective in increasing the participation to control the pregnancy in a muslim community in Indonesia [1]. The are difference result with Studi Natural Family Planning: Physicians, knowledge, attitudes and practice report Most physicians in study underestimated the effectiveness of NFP methods, and only a small proportion physicians provide information about NFP contraceptive counseling [2].

Kelly et. Al report there is a need for increased NFP training for providers and efficient NFP patient teaching strategies to meet the needs of patients with limited knowledge about fertility [3].

There is a significant increase in attitude of the subject after intervention (39-97 point to 56-98 point on average from 75.3 to 80.3 ). There are 25 among subjects is identified giving a support at least moderate support during intervention. Husband's contribution is increasing during intervention on their wife's fertile period (combination between coitus interruptus and condom: 31.2\%, condom: 19.8\%, coitus interruptus: $16.3 \%$, abstinent: 9,3\%). Only 20 times of sexual behavior from subjects that classified as not participating to the pregnancy control. By combining fertility indicators at NFP and use condom at fertile day it can be used in Muslim community, because the most Muslim community can not abstinence.
The percentage of successful abstinence method is only 9.3\% [1]. The application of this method is the least when compared with the other methods. Subjects found that it was difficult to do sexual abstinence on fertile period, since there is a natural increasing of libido which stimulates the increasing of coitus frequency. During the fertile period, women's reproductive hormones dominantly influence their sexual behaviour and aggressiveness. Women's voice is even more interesting during fertile period than the infertile period. Men's response also become very positive against women's sexual behaviour during fertile period. The other factor is their religious belief that sexual intercourse is a higly rewarded worship [1].

Wilcox et al. and Fehring were agree that intercourse patterns among couples occur most frequently during the fertile period [4], [5]. It can occur since woman's libido (sexual interest) is higher during the 6 day fertile period, and man's sexual interest is stimulated by behavior and chemicals (pheromones) from the woman that increases her sexual attractiveness during the period. The prevalence of condom used in China based on the study result of Amory is quite low, it is only 5\% [6]. Meanwhile, Jones et al., also found the number of condom users is lower than coitus interruptus method. He explains that over half of these respondents reported problems with condoms including reduced sexual pleasure, inconvenience, and difficulty using them [7].

Snow et al. explained that using condom makes some women and their partners feel "fake" and it spoils their mood [8]. Jones et al., say by combining two fertility indicators, it can be used in women at all phases of their reproductive life including regular cycles, breast feeding, transition and irregular cycle [7]. Jesha et al., report In North Kerala India $13.5 \%$ used condom [9].

The effectiveness of intervention reached $83.8 \%$ (not pregnant: 31 subjects). The failure rate: $16.2 \%$ (pregnant: 6 subjects), caused by indiscipline sexual behavior during the fertile period: $66.7 \%$ (4 subjects) and miscount fertil period: $33.3 \%$ ( 2 subjects). Fehring et al., report high motivation to avoid pregancy by both the female user a behavioral method of family planning and her male partner is required for high efficacy [10]. Asessing motivation of both the women and her male partner before prescribing NFP methodes is recommended. Adams, say the high level of awareness of natural family planning methods do not give a corresponding encouragement to couples in practising natural family planning methods [11]. Culture and religion plays major role in couples decision to practise natural family planning methods and this is reflected in the husbands dominating in most decision taking by couples in reproductive health issues such as natural family planning matters. Nurfaizah et al., describe that there was a significant correlation between knowledge of reproductive health and family planning to the participation of family planning in women of childbearing age poor families in the city of Makassar [12]. Fennell, show that contraceptive responsibility in long-term relationships in the United States often conforms to a gendered division of labor, with women primarily in charge [13]. A substantial minority of men in this study were highly committed contraceptors. 


\section{CONCLUSION}

Natural family planning with the use of combination condom had influenced the success of Moslem woman's pregnancy through 5 factors: knowledge $(\mathrm{OR}=7)$, support from partners $(\mathrm{OR}=5)$, social norms $(\mathrm{OR}=4)$, belief $(\mathrm{OR}=3)$, and attitude $(\mathrm{OR}=1)$.

\section{REFERENCES}

[1] A. A. Azis, A. A. Djuanna, and M. Chalid, 'The effectiveness of Natural Family Planning Training in increasing participation of Productive-Aged Couple to control pregnancy of moslem community in Indonesia', in Proceedings of The 1st Academic Symposium on Integrating Knowledge (The 1st ASIK): Integrating Knowledge with Science and Religion, 2014.

[2] J. Choi, S. Chan, and E. Wiebe, 'Natural family planning: physicians' knowledge, attitudes, and practice', J. Obstet. Gynaecol. Canada, vol. 32, no. 7, pp. 673-678, 2010.

[3] L. Kelly, 'Family Planning, American Style', Ala. L. Rev., vol. 52, p. 943, 2000.

[4] A. J. Wilcox, D. D. Baird, D. B. Dunson, D. R. McConnaughey, J. S. Kesner, and C. R. Weinberg, 'On the frequency of intercourse around ovulation: evidence for biological influences', Hum. Reprod., vol. 19, no. 7, pp. 1539-1543, 2004.

[5] R. J. Fehring, 'The future of professional education in natural family planning', J. Obstet. Gynecol. Neonatal Nurs., vol. 33, no. 1, pp. 34-43,
2004.

[6] J. K. Amory, 'Reproductive endocrinology: Male hormonal contraceptive passes efficacy test in China', Nat. Rev. Endocrinol., vol. 5, no. 7, pp. 359-360, 2009.

[7] R. K. Jones, J. Fennell, J. A. Higgins, and K. Blanchard, 'Better than nothing or savvy risk-reduction practice? The importance of withdrawal', Contraception, vol. 79, no. 6, pp. 407-410, 2009.

[8] R. Snow et al., 'Attributes of contraceptive technology: womens preferences in seven countries.', 1997.

[9] M. M. Jesha, N. M. Sebastian, S. P. Haveri, and A. S. Nath, 'Unmet needs for family planning in a municipal area in North Kerala, India', Int. J. Reprod. Contraception, Obstet. Gynecol., vol. 5, no. 7, pp. 23222327, 2017.

[10] R. J. Fehring, M. Schneider, M. L. Barron, and J. Pruszynski, 'Influence of motivation on the efficacy of natural family planning', MCN Am.J. Matern. Nurs., vol. 38, no. 6, pp. 352-358, 2013.

[11] Z. B. A. Adams, 'Knowledge, attitude and practice of natural family planning among couples in Kanuda Metropolis'. DEPARTMENT OF SOCIOLOGY, FACULTY OF SOCIAL SCIENCES, AHMADU BELLO UNIVERSITY, ZARIA, 2012.

[12] S. Nurfaizah, W. Thalib, A. A. Azis, and G. D. Dirawan, 'Effect of knowledge and reproductive health of family planning program participation in fertile age women poor families in the city Makassar', Man India, vol. 95, no. 3, pp. 631-637, 2015.

[13] J. L. Fennell, 'Men bring condoms, women take pills men's and women's roles in contraceptive decision making', Gend. Soc., vol. 25 , no. 4, pp. 496-521, 2011. 